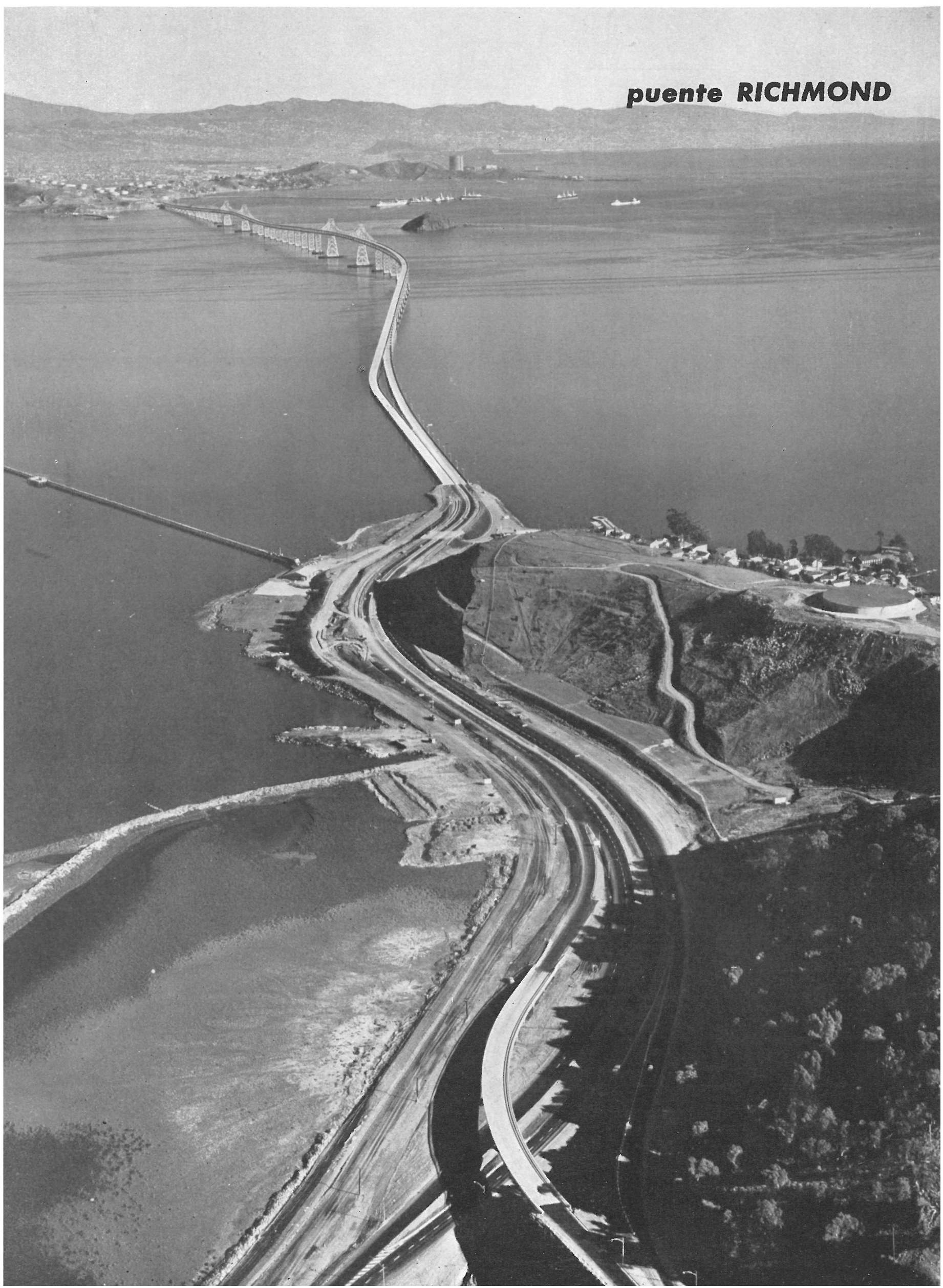




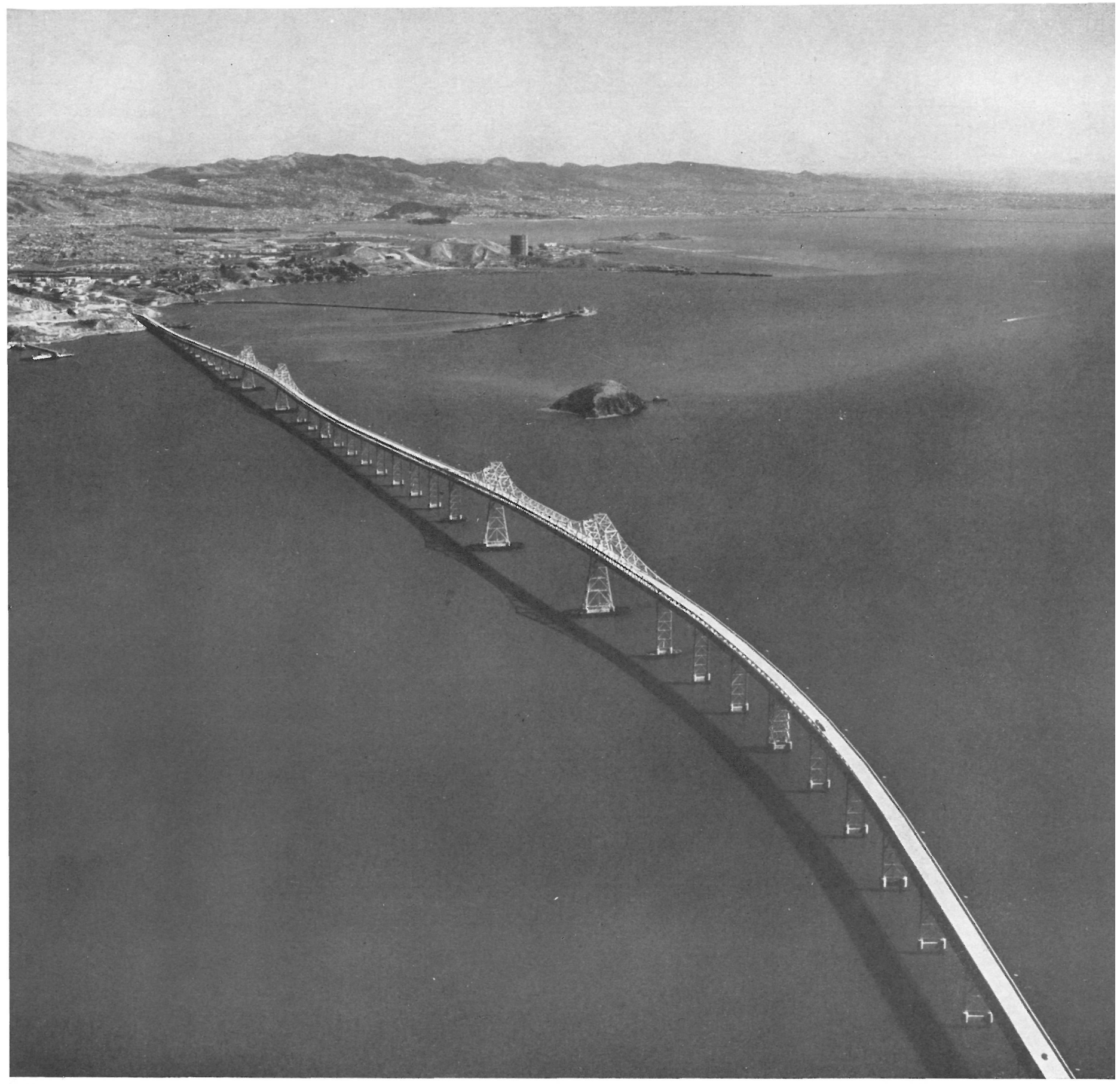

$565 \cdot 8$

\section{puente RICHMOND}

Información amablemente facilitada por el Department of Public Works, State of California.

El puente Richmond-San Rafael, como todas las obras de gran importancia, ha tenido una larga y meditada gestación antes de pasar del estado de anteproyecto al de ejecución.

Su construcción se halla justificada en una imperiosa necesidad de vías de comunicación entre las dos márgenes de la bahía de San Francisco de California, en la zona que separa la población de Richmond de la de San Rafael.

El tráfico por transbordadores entre las dos mencionadas márgenes era tan intenso y, a veces, interrumpido por huelgas y otros accidentes, que las colas de vehículos en espera para cruzar la bahía se hacía interminable. 

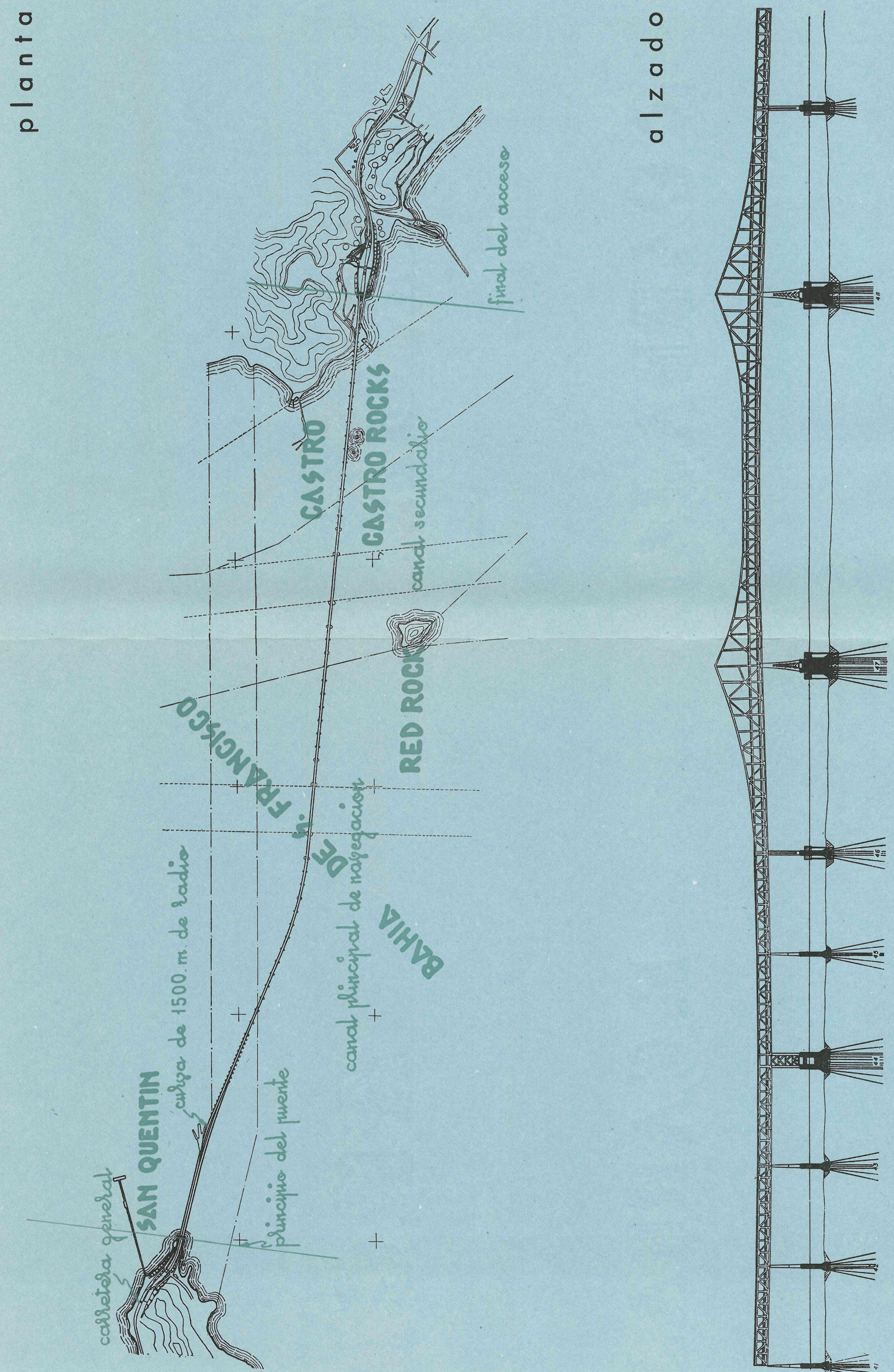


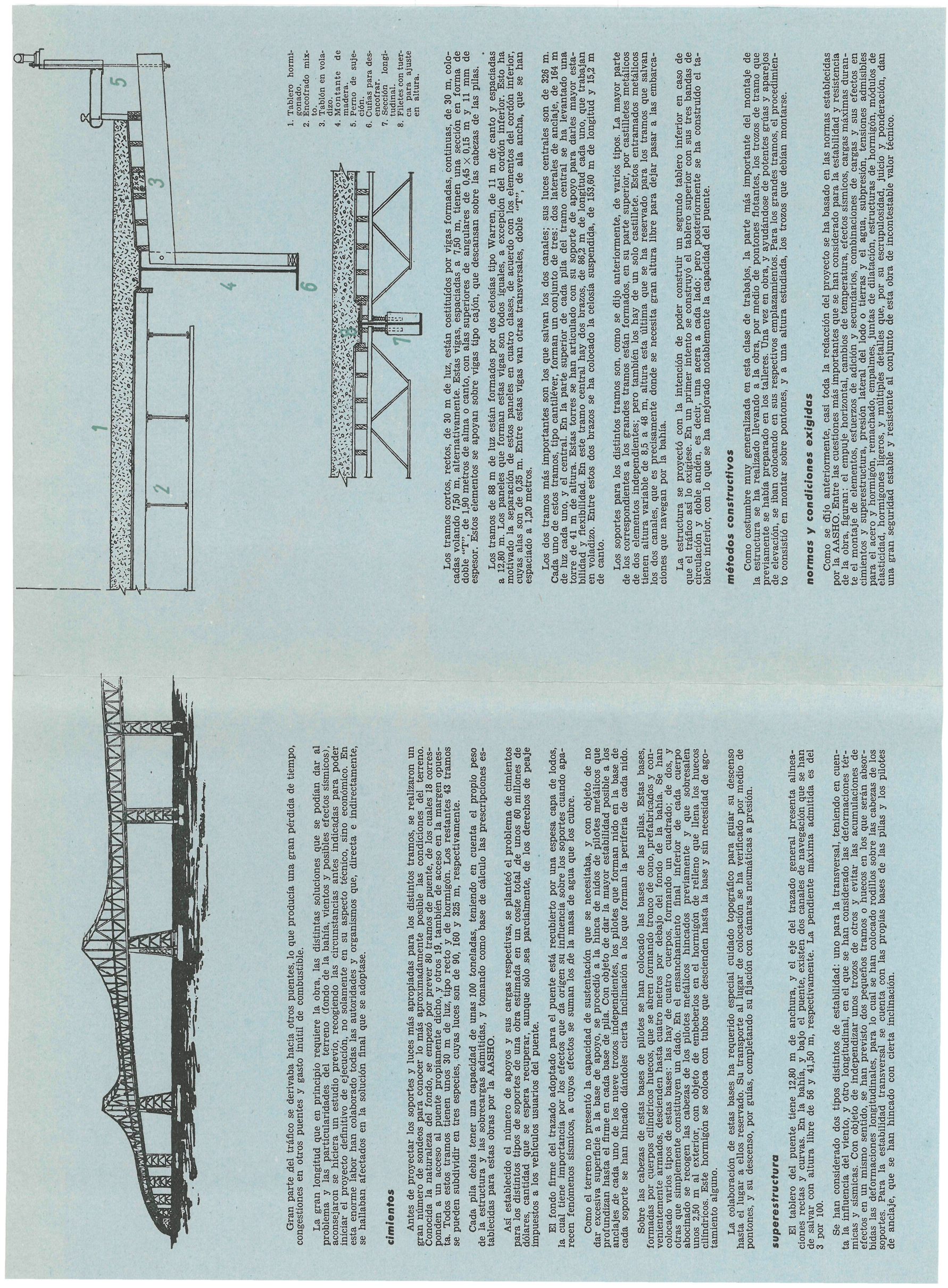




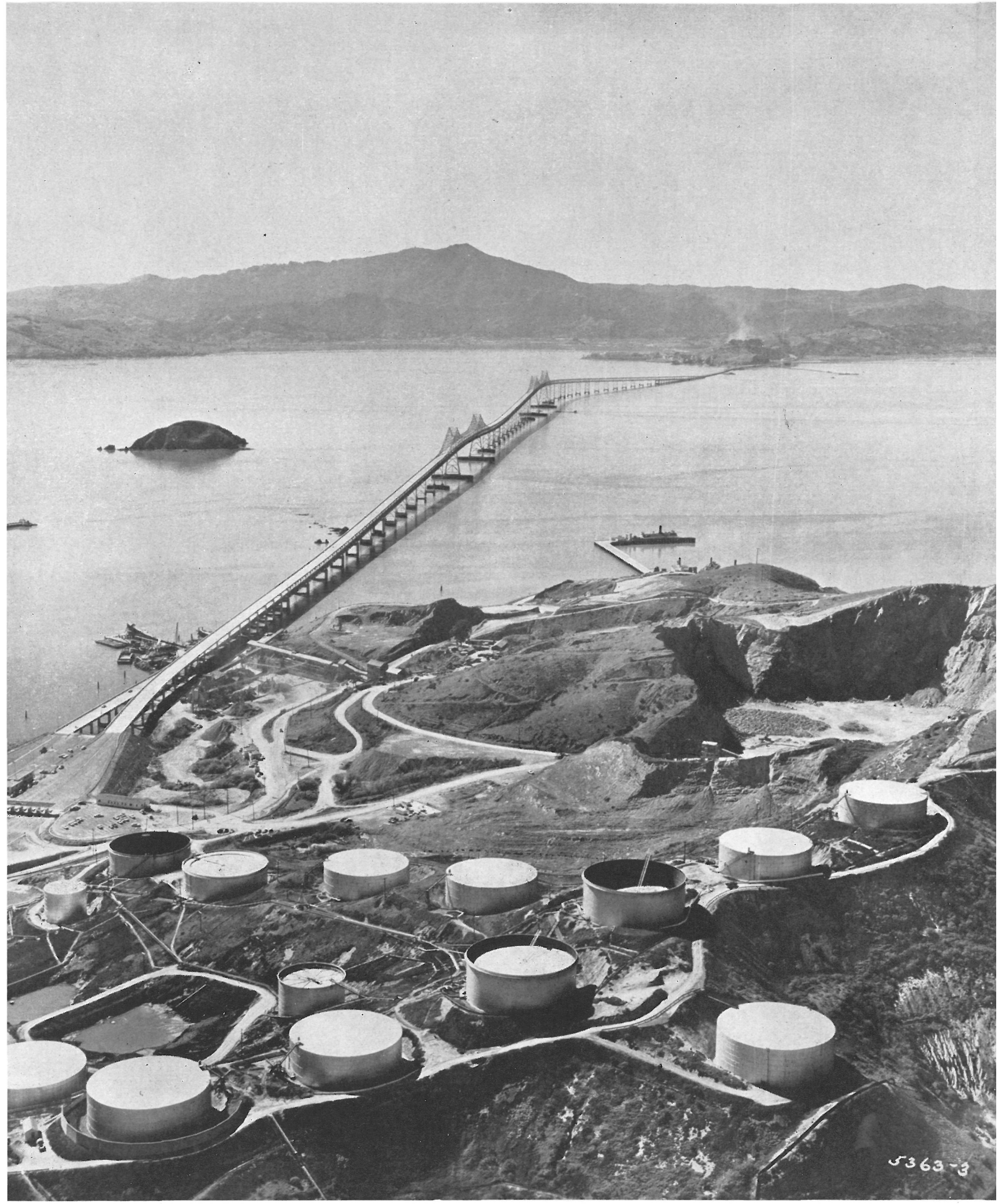

Fotos: CLYDE SUNDERLAND 